\title{
Markovian queues with correlated arrival processes
}

\author{
JEFFREY J. HUNTER \\ Institute of Information \& Mathematical Sciences \\ Massey University at Albany, Auckland, New Zealand
}

\begin{abstract}
In an attempt to examine the effect of dependencies in the arrival process on the steady state queue length process in single server queueing models with exponential service time distribution, four different models for the arrival process, each with marginally distributed exponential interarrivals to the queueing system, are considered. Two of these models are based upon the upper and lower bounding joint distribution functions given by the Fréchet bounds for bivariate distributions with specified marginals, the third is based on Downton's bivariate exponential distribution and fourthly the usual M/M/1 model. The aim of the paper is to compare conditions for stability and explore the queueing behaviour of the different models.
\end{abstract}

\section{Introduction}

Consider a single-server queueing system. Let the instants of arrivals be $0=\mathrm{t}_{0}, \mathrm{t}_{1}, \mathrm{t}_{2}$, $\ldots$, and define the inter-arrival times $T_{n}=t_{n}-t_{n-1}$ for $n \geq 1$.

Assume that the service times are independent and identically distributed (i.i.d.) random variables (r.v.'s) with common distribution function (d.f.), $1-\mathrm{e}^{-\mu \mathrm{x}}, \mathrm{x} \geq 0, \mu>0$.

Various researchers have considered the effect of dependency in the arrival process by making various assumptions concerning the inter-arrival process $\left\{\mathrm{T}_{\mathrm{n}}, \mathrm{n} \geq 1\right\}$.

The simplest model is the usual M/M/1 model whose properties are well known.

Pyke Tin (1985) examined the transient and limiting behaviour of the queue size distribution and the limiting waiting time distribution in the case where $\left\{\mathrm{T}_{\mathrm{n}}\right\}$ is a sequence of Markov dependent r.v.'s. A special case includes the joint distribution between consecutive interarrival-intervals given by Downton's bivariate exponential distribution with joint probability density function (j.p.d.f.)

$$
\mathrm{f}(\mathrm{x}, \mathrm{y})=\frac{\lambda^{2}}{1-\rho} \exp \left\{\frac{-\lambda(x+y)}{1-\rho}\right\} \mathrm{I}_{0}\left(\frac{2 \lambda}{1-\rho} \sqrt{\rho x y}\right)
$$

where $\mathrm{I}_{0}($.$) is a modified Bessel function of the first kind of zero { }^{\text {th }}$ order. The correlation coefficient between $T_{n}$ and $T_{n+1}$ is given by $\rho(0 \leq \rho<1)$ with the $\rho=0$ case corresponding to independent and identically distributed $\left\{\mathrm{T}_{\mathrm{n}}\right\}$, the usual Poisson process input. 
Patuwo, Disney and McNickle (1993) introduced dependency into the arrival process by means of auxiliary r.v.'s associated with arrival types to construct a Markov renewal input whose marginal inter-arrival distribution, in stationarity, is a mixture of Erlang distributions which, with judicious choice of parameters, can approximate the exponential distribution.

In both these aforementioned papers it is shown that the introduction of dependency can have a major effect on queue lengths especially as the serial coefficient and the traffic intensity increases. The increase in mean queue length in the Patuwo, Disney and McNickle model can be quite marked for even moderate values of .

Earlier studies of correlated arrival queues can be found in Gopinath and Morrison (1977), Latouche (1981), (1985) and Runnenburg (1961), (1962). For some simulation studies of the effects of autocorrelation in queues see Livny, Melamed and Tsiolis (1993). See also the work of Sriram and Whitt (1986) for evidence of dependence among successive inter-arrival times in packet mutiplexers for voice and data.

The approach taken in this paper is to generate the $\left\{\mathrm{T}_{n}\right\}$ inter-arrival process with each pair of r.v.'s $\left(T_{n}, T_{n+1}\right),(n \geq 1)$, being sampled from a specified joint d.f. $F(x, y)$. This mechanism will enable us to compare the effect of different first order dependent correlated inter-arrival times on the queueing behaviour of various models.

In effect, this means that once $T_{1}, T_{2}, \ldots, T_{n}$ have been generated, $T_{n+1}$ is generated by the conditional d.f. of $T_{n+1}$ given $T_{n}$. In order to compare our results with those obtained from the usual Poisson input process we require that the marginal d.f. of each $T_{n}$ r.v. be exponential, with form $1-\mathrm{e}^{-\lambda \mathrm{x}}, \mathrm{x} \geq 0, \lambda>0$.

It can be shown (Hoeffding (1940); Fréchet (1951)), that every joint d.f. with fixed marginals can be bounded above and below by two j.d.f.'s determined solely by the marginals as given by the following Lemma.

\section{Lemma 1.1:}

Let $(X, Y)$ be r.v.'s with joint d.f. $F(x, y)$ and specified marginal d.f.'s $F_{1}(x)$ and $F_{2}(y)$ for $\mathrm{X}$ and $\mathrm{Y}$ respectively. Then

$$
\mathrm{A}(\mathrm{x}, \mathrm{y}) \leq \mathrm{F}(\mathrm{x}, \mathrm{y}) \leq \mathrm{B}(\mathrm{x}, \mathrm{y}) \text { for all } \mathrm{x},
$$

where the j.d.f.'s $A$ and $B$ are given by

$$
\begin{aligned}
& \mathrm{A}(\mathrm{x}, \mathrm{y})=\max \left\{\mathrm{F}_{1}(\mathrm{x})+\mathrm{F}_{2}(\mathrm{y})-1,0\right\} \\
& \mathrm{B}(\mathrm{x}, \mathrm{y})=\min \left\{\mathrm{F}_{1}(\mathrm{x}), \mathrm{F}_{2}(\mathrm{y})\right\}
\end{aligned}
$$

We examine various models, each with marginal d.f.'s $F_{1}(x)=1-e^{-\lambda x}, x \geq 0$ and $F_{2}(y)=$ $1-\mathrm{e}^{-\lambda \mathrm{y}}, \mathrm{y} \geq 0$. 
Model 1: $F(x, y)$ taken as the j.d.f. corresponding to independent exponential distributions, i.e.,

$$
F(x, y)=\left\{1-e^{-\lambda x}\right\}\left\{1-e^{-\lambda y}\right\}, \quad x \geq 0, y \geq 0 .
$$

Model 2: $\quad F(x, y)$ taken as the upper Fréchet bound $B(x, y)$, i.e.

$$
\mathrm{B}(\mathrm{x}, \mathrm{y})=\min \left\{1-\mathrm{e}^{-\lambda \mathrm{x}}, 1-\mathrm{e}^{-\lambda \mathrm{y}}\right\}, \quad \mathrm{x} \geq 0, \mathrm{y} \geq 0 .
$$

Model 3: $\quad F(x, y)$ taken as the lower Fréchet bound $A(x, y)$, i.e.

$$
A(x, y)=\max \left\{1-e^{-\lambda x}-e^{-\lambda y}, 0\right\}, \quad x \geq 0, y \geq 0 .
$$

Model 4: $\quad F(x, y)$ taken as the j.d.f. corresponding to Downton's bivariate exponential distribution with p.d.f. given by (1.1).

In this paper we investigate queueing models with arrival processes having successive inter-arrival times generated by the above bivariate processes and examine the effects that such arrival processes will have on the congestion in the resulting queueing system. As noted above, the bivariate distributions $\mathrm{A}(\mathrm{x}, \mathrm{y})$ and $\mathrm{B}(\mathrm{x}, \mathrm{y})$ are extreme cases, being lower and upper bounds for all joint distributions with specified marginals. Is this behaviour some how reflected in the queueing models constructed with such arrival processes?

In order to explore these questions we first examine the properties of these bounding joint d.f.'s. We then follow this up with the implications of these results when the interarrival time process $\left\{T_{n}\right\}$ is constructed with each pair of r.v.'s $\left(T_{n}, T_{n+1}\right),(n \geq 1)$, being sampled from a specified joint d.f. $F(x, y)$ whose marginal d.f's are both $1-e^{-\lambda x}$, $\mathrm{x} \geq 0, \quad \lambda>0$.

\section{Joint distributions with specified marginals}

The bounds on two-dimensional d.f.'s given by (1.2) have been used in the construction of bounds on two dimensional renewal functions in Hunter (1977). In that paper various key properties of the upper and lower bounding d.f.'s were explored. We summarise the relevant results in the situation when $F_{1}(x)=1-e^{-\lambda x}, x \geq 0$, and $\mathrm{F}_{2}(\mathrm{y})=1-\mathrm{e}^{-\lambda \mathrm{y}}, \mathrm{y} \geq 0$.

Since both $F_{1}(x)$ and $F_{2}(y)$ are continuous non-decreasing d.f.'s, by considering the rectangles $\left\{(\mathrm{x}, \mathrm{y}): \mathrm{x}_{1}<\mathrm{x} \leq \mathrm{x}_{2}, \mathrm{y}_{1}<\mathrm{y} \leq \mathrm{y}_{2}\right\}$ it is easily seen that all the probability mass 
for the j.d.f. $A(x, y)$ lies on the curve $F_{1}(x)+F_{2}(y)-1=0$, i.e. on the curve $e^{-\lambda x}+e^{-\lambda y}$ $=1$.

Similarly, all the probability mass for the j.d.f. $B(x, y)$ lies on the curve $F_{1}(x)=F_{2}(y)$, i.e. on the line $\mathrm{x}=\mathrm{y}$. These results imply functional relationships between the r.v.'s $\mathrm{X}$ and $\mathrm{Y}$ :

\section{Lemma 2.1:}

(a) If $X$ has the d.f. $F_{1}(x)=1-e^{-\lambda x}, x \geq 0$ and $Y \equiv X$, then $Y$ has d.f. $F_{2}(y)=1-e^{-\lambda y}$, $\mathrm{y} \geq 0$, and $(X, Y)$ has the j.d.f. $B(x, y)$ given by (1.4).

(b) If $X$ has the d.f. $F_{1}(x)=1-e^{-\lambda x}, x \geq 0$ and $Y \equiv-\frac{1}{\lambda} \ln \left(1-e^{-\lambda X}\right)$, or $e^{-\lambda X}-e^{-\lambda Y}=$ 1 , then $Y$ has the d.f. $F_{2}(y)=1-e^{-\lambda y}, y \geq 0$, and $(X, Y)$ has the j.d.f. $A(x, y)$ given by (1.5).

Proof: See Lemma 2.2, Hunter (1977).

O

Thus $\mathrm{A}(\mathrm{x}, \mathrm{y})$ and $\mathrm{B}(\mathrm{x}, \mathrm{y})$ are both singular continuous distributions in two dimensions but with absolutely continuous marginals, in contrast to the absolutely continuous distribution corresponding to the special case with j.p.d.f. $f(x, y)$ given by (1.1).

By using the distribution functions $\mathrm{F}(\mathrm{x}, \mathrm{y})$ with j.d.f. given by (1.3), $\mathrm{A}(\mathrm{x}, \mathrm{y})$ given by (1.5), $\mathrm{B}(\mathrm{x}, \mathrm{y})$ given by (1.4), and $\mathrm{F}(\mathrm{x}, \mathrm{y})$ with j.p.d.f. given by (1.1) we hope to obtain a variety of special cases that will give a coverage of possible bivariate exponential distributions. In particular, concerning the correlations between the $X$ and Y r.v.'s we have the following results.

\section{Lemma 2.2:}

Let $\rho=\operatorname{corr}(X, Y)$.

(a) For $(X, Y)$ with j.d.f. $F(x, y)$ given by $(1.3), \rho=0$.

(b) For $(\mathrm{X}, \mathrm{Y})$ with j.d.f. $\mathrm{B}(\mathrm{x}, \mathrm{y})$ given by (1.4), $\rho=1$.

(c) For $(X, Y)$ with j.d.f. $A(x, y)$ given by (1.5), $\rho=1-\frac{\pi^{2}}{6} \approx-0.645$.

(d) For (X, Y) with j.p.d.f. $f(x, y)$ given by (1.1), $0 \leq \rho<1$.

Proof: Parts (a), (b) and (d) follow easily. 
For (c) observe that $\mathrm{E}[\mathrm{XY}]=\mathrm{E}_{\mathrm{X}}[\mathrm{X} \mathrm{E}[\mathrm{Y} \mid \mathrm{X}]]=\mathrm{E}\left[-X\left(\frac{1}{\lambda} \ln \left(1-e^{-\lambda X}\right)\right)\right\rfloor$

$$
=\int_{0}^{\infty} x\left\{-\frac{1}{\lambda} \ln \left(1-e^{-\lambda x}\right) \lambda e^{-\lambda x}\right\} d x=\frac{1}{\lambda^{2}}\left(2-\frac{\pi^{2}}{6}\right),
$$

where we have used the transformation $\mathrm{z}=\mathrm{e}^{-\lambda \mathrm{x}}$. The result now follows since $\mathrm{E}[\mathrm{X}]=$ $\mathrm{E}[\mathrm{Y}]=1 / \lambda ; \operatorname{var}(\mathrm{X})=\operatorname{var}(\mathrm{Y})=1 / \lambda^{2}$.

The correlation coefficient for $\mathrm{A}(\mathrm{x}, \mathrm{y})$ is the smallest possible for any pair of correlated exponential r.v.'s (see Moran (1967)). For (a), when $\rho=0$ the r.v.'s are independent. The maximum possible correlation occurs for $\mathrm{B}(\mathrm{x}, \mathrm{y})$, when $\rho=1$.

\section{The queueing models}

When considering queueing models with exponential service times we typically explore the queue lengths embedded at arrival times.

Let $X(t)=$ Number of customers in the queueing system at time $t$, let $X_{n}=X\left(t_{n^{-}}\right)$, the number of customers in the system immediately before the arrival of the nth customer.

Let us digress to consider results for the GI/M/1 queueing system, where the interarrival times are generated by a sequence of i.i.d. r.v.'s from a d.f. A(x), with mean $1 / \lambda$, (so that the arrival rate is $\lambda$ customers per unit time).

It is well known that $\left\{X_{n}, n \geq 1\right\}$ is homogenous first order Markov chain. The analysis of this Markov chain is effected by considering the relationship:

$$
\mathrm{X}_{\mathrm{n}+1}=\mathrm{X}_{\mathrm{n}}+1-\mathrm{B}_{\mathrm{n}}, \quad\left(0 \leq \mathrm{B}_{\mathrm{n}} \leq \mathrm{X}_{\mathrm{n}}+1, \mathrm{X}_{\mathrm{n}} \geq 0\right)
$$

where $B_{n}=$ Number of customers served during the interarrival time $T_{n+1}=t_{n+1}-t_{n}$.

Let $\mathrm{p}_{\mathrm{ij}}=\mathrm{P}\left\{\mathrm{X}_{\mathrm{n}+1}=\mathrm{j} \mid \mathrm{X}_{\mathrm{n}}=\mathrm{i}\right\}$ be the one step transition probability of the M.C.

Then $p_{i j}=\left\{\begin{array}{lc}P\left\{B_{n}=i-j+1 \mid X_{n}=i\right\}, & \text { for } i \geq 0 \text { and } 0 \leq j \leq i+1 \\ 0, & \text { otherwise. }\end{array}\right.$

Note that for this model, $B_{n}$ depends only on the length of the interval $T_{n+1}$ and not on the extent of the service the customer present in the system has received, because of the lack of memory of the exponential service times. 
If $j>0$, (i.e. $X_{n+1}>0$ ) there is still a customer in the system and the server must have been busy during the whole interval $U_{n+1}$. Thus, for $0<j \leq i+1, i \geq 0$ we have

$$
\begin{aligned}
\mathrm{p}_{\mathrm{ij}}=\mathrm{P}\left\{\mathrm{B}_{\mathrm{n}}=\mathrm{i}-\mathrm{j}+1\right\} & =\int_{0}^{\infty} \mathrm{P}\left\{\mathrm{B}_{\mathrm{n}}=\mathrm{i}-\mathrm{j}+1 \mid \mathrm{T}_{\mathrm{n}+1}=\mathrm{t}\right\} \mathrm{dA}(\mathrm{t}) \\
& =\int_{0}^{\infty} \frac{\mathrm{e}^{-\mu \mathrm{t}}(\mu \mathrm{t})^{\mathrm{i}-\mathrm{j}+1}}{(\mathrm{i}-\mathrm{j}+1) !} \mathrm{dA}(\mathrm{t})=\mathrm{k}_{\mathrm{i}-\mathrm{j}+1} \text {, say }
\end{aligned}
$$

since if the server is fully occupied the service process is a Poisson process of rate $\mu$.

For $\mathrm{i} \geq 0,(\mathrm{j}=0)$, since $\left\{\mathrm{k}_{\mathrm{n}}\right\}$ forms a probability distribution, $\mathrm{p}_{\mathrm{i} 0}=1-\sum_{\mathrm{r}=0}^{\mathrm{i}} \mathrm{k}_{\mathrm{r}} \equiv \alpha_{\mathrm{i}}$.

Thus the transition matrix of the embedded M.C. is given by

$$
\mathrm{P}=\left[\begin{array}{cccccccc}
\alpha_{0} & \mathrm{k}_{0} & 0 & 0 & 0 & . & . & . \\
\alpha_{1} & \mathrm{k}_{1} & \mathrm{k}_{0} & 0 & 0 & . & . & . \\
\alpha_{2} & \mathrm{k}_{2} & \mathrm{k}_{1} & \mathrm{k}_{0} & 0 & & & \\
\cdot & \cdot & \cdot & \cdot & . & . & & \\
\cdot & . & \cdot & . & . & . & . & \\
\cdot & . & . & . & . & . & . & .
\end{array}\right] .
$$

It is easily seen that $\left\{X_{n}, \mathrm{n} \geq 0\right\}$ is irreducible $\Leftrightarrow 0<\mathrm{k}_{0} \leq \mathrm{k}_{0}+\mathrm{k}_{1}<1$.

Further if $\left\{X_{n}, n \geq 0\right\}$ is irreducible it is aperiodic.

$$
\rho \equiv \frac{\text { mean service time }}{\text { mean inter arrival time }}=\frac{1 / \mu}{1 / \lambda}=\frac{\lambda}{\mu}=\left(\frac{1}{\sum_{\mathrm{j}=1}^{\infty} \mathrm{jk}}\right) \text {. }
$$

The MC is $\left\{\begin{array}{l}\text { transient if } \rho>1 \\ \text { persistent null if } \rho=1 \\ \text { persistent non - null(ergodic) if } \rho<1 .\end{array}\right.$

The stationary distribution of the irreducible Markov chain $\left\{X_{n}, n \geq 0\right\}$ is given by $\pi_{j}=(1-r) r^{j},(j \geq 0)$, where $r$ is the unique root in $(0,1)$ of $z=K(z)=\sum_{j=0}^{\square} k_{j} z^{j}$.

Observe that $K(z)=\sum_{j=0}^{\infty} k_{j} z^{j}=\sum_{j=0}^{\infty} \int_{0}^{\infty} \frac{e^{-\mu t}(\mu t)^{j} z^{j}}{j !} d A(t)=\int_{0}^{\infty} e^{-\mu t(1-z)} d A(t)$.

i.e. $\quad \mathrm{K}(\mathrm{z})=\mathrm{A} *(\mu(1-\mathrm{z}))$, where $\mathrm{A} *(\mathrm{~s})$ is the LST of $\mathrm{A}(\mathrm{t})$.

\subsection{Model 1: The M/M/1 queue}

Using the results above it is easy to verify that, provided $\rho<1,\left\{X_{n}, n \geq 0\right\}$ is an irreducible Markov chain with transition probabilities given by 
$P\left\{X_{n+1}=j \mid X_{n}=i\right\}=P\left\{B_{n+1}=i+1-j\right\}=\int_{0}^{\infty} \frac{e^{-\mu x}(\mu x)^{i+1-j}}{(i+1-j) !} \lambda e^{-\lambda x} d x=k_{i+1-j}$

Note that $\mathrm{k}_{\mathrm{j}}=\left(\frac{\lambda}{\lambda+\mu}\right)\left(\frac{\mu}{\lambda+\mu}\right)^{\mathrm{j}}, \mathrm{j}=0,1,2, \ldots$; and $\mathrm{K}(\mathrm{z})=\frac{\lambda}{\lambda+\mu(1-\mathrm{z})}$.

Further, $A^{*}(s)=\int_{0}^{\infty} e^{-s t} \lambda e^{-\lambda t} d t=\frac{\lambda}{\lambda+s}$, and solving $K(z)=z$ yields $r=\rho$, and hence the queue length process embedded immediately before an arrival has a stationary distribution $\left\{\pi_{\mathrm{j}}\right\}$, with

and mean $\mathrm{L}=1 / \rho$.

$$
\pi_{j}=(1-\rho) \rho^{j},(j \geq 0),
$$

For this model it is also well known that, provided $\rho<1$, the queue length embedded immediately after a departure, and at an arbitrary time point, also has the above geometric distribution, under stationary conditions.

\subsection{Model 2: The upper Fréchet bound}

For this model the successive inter-arrival intervals $\left(\mathrm{T}_{\mathrm{n}}, \mathrm{T}_{\mathrm{n}+1}\right)$ are sampled from the bivariate d.f. $\mathrm{B}(\mathrm{x}, \mathrm{y})$ given by (1.4). As a consequence of Lemma 2.1(a), given $\mathrm{T}_{\mathrm{n}}=\mathrm{x}$, we have that $T_{n+1}=x$. Thus once $T_{1}$ has been obtained, as an exponential r.v. with mean $1 / \lambda$, all the subsequent inter-arrival intervals are determined identical to $T_{1}$.

Thus conditional upon $\mathrm{T}_{1}=\mathrm{x}$, the queueing model is in fact a $\mathrm{D} / \mathrm{M} / 1$ queue.

Given $\mathrm{T}_{1}=\mathrm{x}, \mathrm{b} \equiv \frac{\text { mean service time }}{\text { mean inter - arrival time }}=\frac{1}{\mu \mathrm{x}}$.

The system will be stable $\Leftrightarrow \mathrm{b}<1 \Leftrightarrow \mu>\frac{1}{x} \Leftrightarrow x>\frac{1}{\mu}$.

The system will be unstable $\Leftrightarrow \mathrm{b} \geq 1 \Leftrightarrow \mu \leq \frac{1}{x} \Leftrightarrow x \leq \frac{1}{\mu}$, with $\mathrm{L}=\infty$.

\section{Lemma 3.1:}

For the queueing system with arrival process governed by the joint inter-arrival distribution $\mathrm{B}(\mathrm{x}, \mathrm{y})$,

$$
\mathrm{P}\{\text { System is stable }\}=\exp (-\lambda / \mu) \text {. }
$$

Proof: Since $\mathrm{x}$ is the observed value of $\mathrm{X}=\mathrm{T}_{1}$ an exponential $(\lambda)$ r.v.,

$\mathrm{P}\{$ System stable $\}=\mathrm{P} .\{\mu \mathrm{X}>1\}=\mathrm{P}\{\mathrm{X}>1 / \mu\}=\exp (-\lambda / \mu)$. 
Under the stable scenario, a limiting distribution will exist, with finite mean L.

The underlying bivariate process $\left\{\mathrm{X}_{\mathrm{n}}, \mathrm{T}_{\mathrm{n}}\right\}$ is a Markov process since

$$
\begin{aligned}
& P\left\{X_{n+1}=j, T_{n+1} \leq t \mid X_{0}, X_{1}, \ldots, X_{n}=i ; T_{1}, T_{2}, \ldots, T_{n}=x\right\} \\
& =P\left\{X_{n+1}=j, T_{n+1} \leq t \mid X_{n}=i, T_{n}=x\right\},
\end{aligned}
$$

with $X_{n+1}$ being determined through $X_{n}$ and $T_{n+1}$, and $T_{n+1}$ being determined through $\mathrm{T}_{\mathrm{n}}$.

Observe that for this model, since $\left\{\mathrm{T}_{1}=\mathrm{x}\right\} \equiv\left\{\mathrm{T}_{\mathrm{n}+1}=\mathrm{x}\right\}$,

$$
\begin{aligned}
P\left\{X_{n+1}=j \mid X_{n}=i\right\} & =\int_{0}^{\infty} P\left\{X_{n+1}=j, T_{n+1} \in(x, x+d x) \mid X_{n}=i\right\} \\
& =\int_{0}^{\infty} P\left\{X_{n+1}=j \mid X_{n}=i, T_{n+1}=x\right\} d F_{1}(x)
\end{aligned}
$$

For $1 \leq \mathrm{j} \leq \mathrm{i}+1$, using relationship (3.1),

$\mathrm{P}\left\{\mathrm{X}_{\mathrm{n}+1}=\mathrm{j} \mid \mathrm{X}_{\mathrm{n}}=\mathrm{i}, \mathrm{T}_{\mathrm{n}+1}=\mathrm{x}\right\}=\mathrm{P}\left\{\mathrm{B}_{\mathrm{n}}=\mathrm{i}+1-\mathrm{j} \mid \mathrm{T}_{\mathrm{n}+1}=\mathrm{x}\right\}=\frac{e^{-\mu x}(\mu x)^{i+1-j}}{(i+1-j) !}$,

so that,

$$
\mathrm{P}\left\{\mathrm{X}_{\mathrm{n}+1}=\mathrm{j} \mid \mathrm{X}_{\mathrm{n}}=\mathrm{i}\right\}=\int_{0}^{\infty} \frac{e^{-\mu x}(\mu x)^{i+1-j}}{(i+1-j) !} \lambda \mathrm{e}^{-\lambda \mathrm{x}} \mathrm{dx}=\mathrm{k}_{\mathrm{i}}+1-\mathrm{j},
$$

as given for the $\mathrm{M} / \mathrm{M} / 1$ model in expression (3.3). The result for $\mathrm{j}=0$ follows analogously.

Consequently, the one step transition probabilities of $\left\{X_{n}\right\}$ process are identical to those obtained for the usual M/M/1 model.

Note however that this does not necessarily imply that the $\left\{X_{n}\right\}$ process is a Markov chain nor that the stationary distribution of the $\left\{X_{n}\right\}$ process is the same as that given by (3.4).

Using the results above for the GI/M/1 queue with $\mathrm{GI}=\mathrm{D}$, it is easy to verify, provided $<1$, i.e. $\mu \mathrm{x}>1$, that conditional upon $\mathrm{T}_{1}=\mathrm{x},\left\{\mathrm{X}_{\mathrm{n}}, \mathrm{n} \geq 0\right\}$ is an irreducible Markov chain.

Further, since $A(t)=\left\{\begin{array}{ll}1, & t \geq x \\ 0, & t<x\end{array}, A^{*}(s)=\int_{0}^{\infty} e^{-s t} d A(t)=e^{-s x}\right.$, and solving, $K(z)=A^{*}(\mu(1-z))=e^{-\mu(1-z) x}=z$ when $\mu x>1$, yields a root $z=r \in(0,1)$. 
Hence the queue length process embedded immediately before an arrival has a stationary distribution $\left\{\pi_{\mathrm{j}}\right\}$, with $\pi_{\mathrm{j}}=(1-\mathrm{r}) \mathrm{j},(\mathrm{j} \geq 0)$ and mean $\mathrm{L}=1 / \mathrm{r}$.

\subsection{Model 3: The lower Fréchet bound}

For this model the successive inter-arrival intervals $\left(T_{n}, T_{n+1}\right)$ are sampled from the bivariate d.f. $\mathrm{A}(\mathrm{x}, \mathrm{y})$ given by (1.4). As a consequence of Lemma 2.1(b), given $\mathrm{T}_{\mathrm{n}}=\mathrm{x}$ we have that $\mathrm{T}_{\mathrm{n}+1}=-\frac{1}{\lambda} \ln \left(1-\mathrm{e}^{-\lambda \mathrm{x}}\right) \equiv \mathrm{y}$, say. Thus once $\mathrm{T}_{1}=\mathrm{x}$ has been obtained, as an exponential r.v. with mean $1 / \lambda, \mathrm{T}_{2}=\mathrm{y}$ and $\mathrm{T}_{3}=-\frac{1}{\lambda} \ln \left(1-\mathrm{e}^{-\lambda \mathrm{y}}\right) \equiv \mathrm{z}$. This implies that $\mathrm{e}^{-\lambda \mathrm{z}}=1-\mathrm{e}^{-\lambda \mathrm{y}}$, but $\mathrm{e}^{-\lambda \mathrm{y}}=1-\mathrm{e}^{-\lambda \mathrm{x}}$ so that $\mathrm{e}^{-\lambda \mathrm{z}}=\mathrm{e}^{-\lambda \mathrm{x}}$ or $\mathrm{z}=\mathrm{x}$, i.e. $\mathrm{T}_{3} \equiv \mathrm{T}_{1}$. The generation of the inter-arrival sequence is consequently an alternating sequence with $T_{1}$ $=x, T_{2}=y, T_{3}=x, T_{4}=y$ etc where $e^{-\lambda x}+e^{-\lambda y}=1$.

As before, the underlying bivariate process $\left\{\mathrm{X}_{\mathrm{n}}, \mathrm{T}_{\mathrm{n}}\right\}$ is a Markov process. However for this model, we need to consider odd and even numbered transactions to determine the probability $P\left\{X_{n+1}=j \mid X_{n}=i\right\}$.

First observe that for $1<\mathrm{j} \leq \mathrm{i}+1$,

$$
\begin{aligned}
P\left[X_{1}=j \mid X_{0}=i\right] & =\int_{0}^{\infty} P\left[X_{1}=j, T_{1} \in(x, x+d x) \mid X_{0}=i\right] \\
& =\int_{0}^{\infty} P\left[X_{1}=j \mid X_{0}=i, T_{1}=x\right] d F(x) \\
& =\int_{0}^{\infty} \frac{e^{-\mu x}(\mu x)^{i+1-j}}{(i+1-j) !} \lambda \mathrm{e}^{-\lambda x} d x \\
& =\mathrm{k}_{\mathrm{i}+1-\mathrm{j}}, \text { as in (3.3) for } \mathrm{n}=0 .
\end{aligned}
$$

Secondly, for $1 \leq \mathrm{j} \leq \mathrm{i}+1$,

$$
\begin{aligned}
P\left[X_{2}=j \mid X_{1}=i\right] & =\int_{0}^{\infty} P\left[X_{2}=j, T_{1} \in(x, x+d x) \mid X_{1}=i\right] \\
& =\int_{0}^{\infty} P\left[X_{2}=j \mid X_{1}=i, T_{1}=x\right] d F_{1}(x) .
\end{aligned}
$$

But $\left\{\mathrm{T}_{1}=\mathrm{x}\right\} \equiv\left\{\mathrm{T}_{2}=\mathrm{y}\right\}$ where $\mathrm{e}^{-\lambda \mathrm{x}}+\mathrm{e}^{-\lambda \mathrm{y}}=1$, thus 


$$
\begin{aligned}
P\left[X_{2}=j \mid X_{1}=i\right] & =\int_{0}^{\infty} P\left[X_{2}=j \mid X_{1}=i, T_{2}=y\right] d F_{1}(x) \\
& =\int_{0}^{\infty} \frac{e^{-\mu y}(\mu y)^{i+1-j}}{(i+1-j) !} \lambda e^{-\lambda x} d x .
\end{aligned}
$$

Substitute $\mathrm{e}^{-\lambda \mathrm{x}}=1-\mathrm{e}^{-\lambda \mathrm{y}}$, implying $-\lambda \mathrm{e}^{-\lambda \mathrm{x}} \mathrm{dx}=\lambda \mathrm{e}^{-\lambda \mathrm{y}} \mathrm{dy}$ and thus

$$
\begin{aligned}
\mathrm{P}\left[\mathrm{X}_{2}=\mathrm{j} \mid \mathrm{X}_{1}=\mathrm{i}\right] & =\int_{0}^{\infty} \frac{\left(1-e^{-\lambda x}\right)^{\mu / \lambda}\left\{-\frac{\mu}{\lambda} \ln \left(1-e^{-\lambda x}\right)\right\}^{i+1-j}}{(i+1-j) !} \lambda \mathrm{e}^{-\lambda \mathrm{x}} \mathrm{dx} . \\
& =\int_{0}^{\infty} \frac{e^{-\mu x}(\mu x)^{i+1-j}}{(i+1-j) !} \lambda \mathrm{e}^{-\lambda \mathrm{y}} \mathrm{dy} \\
& =\mathrm{k}_{\mathrm{i}+1-\mathrm{j}}, \text { as in }(3.3) \text { for } \mathrm{n}=1 .
\end{aligned}
$$

This procedure can be generalised as follows:

$$
P\left[X_{n+1}=j \mid X_{n}=i\right]=\int_{0}^{\infty} P\left[X_{n+1}=j \mid X_{n}=i, T_{1}=x \lambda e^{-\lambda x} d x .\right.
$$

If $\mathrm{n}$ is even, $\left\{\mathrm{T}_{1}=\mathrm{x}\right\} \equiv\left\{\mathrm{T}_{\mathrm{n}+1}=\mathrm{x}\right\}$, while if $\mathrm{n}$ is odd, $\left\{\mathrm{T}_{1}=\mathrm{x}\right\} \equiv\left\{\mathrm{T}_{\mathrm{n}+1}=\mathrm{y}\right\}$ where $\mathrm{e}^{-\lambda \mathrm{x}}+\mathrm{e}^{-\lambda \mathrm{y}}=1$.

In the $n$ even case, for $1 \leq \mathrm{j} \leq \mathrm{i}+1$,

$$
\begin{aligned}
\mathrm{P}\left[\mathrm{X}_{\mathrm{n}+1}=\mathrm{j} \mid \mathrm{X}_{\mathrm{n}}=\mathrm{i}\right] & =\int_{0}^{\infty} \mathrm{P}\left[\mathrm{X}_{\mathrm{n}+1}=\mathrm{j} \mid \mathrm{X}_{\mathrm{n}}=\mathrm{i}, \mathrm{T}_{\mathrm{n}+1}=\mathrm{x}\right] \lambda \mathrm{e}^{-\lambda \mathrm{x}} \mathrm{dx} \\
& =\int_{0}^{\infty} \frac{e^{-\mu x}(\mu x)^{i+1-j}}{(i+1-j) !} \lambda \mathrm{e}^{-\lambda \mathrm{x}} \mathrm{dx} \\
& =\mathrm{k}_{\mathrm{i}+1-\mathrm{j}}, \text { as in }(3.3) .
\end{aligned}
$$

While for $n$ odd case, for $1 \leq \mathrm{j} \leq \mathrm{i}+1$,

$$
\begin{aligned}
P\left[X_{n+1}=j \mid X_{n}=i\right] & =\int_{0}^{\infty} P\left[X_{n+1}=j \mid X_{n}=i, T_{n+1}=-\frac{1}{\lambda} \ln \left(1-e^{-\lambda x}\right)\right] \lambda e^{-\lambda x} d x \\
& =k_{i+1-j}, \text { as in (3.3). }
\end{aligned}
$$

Consequently, for all $n, 1 \leq j \leq i+1, P\left[X_{n+1}=j \mid X_{n}=i\right]=k_{i}+1-j$, as given for the $\mathrm{M} / \mathrm{M} / 1$ model in expression (3.3). The results for $\mathrm{j}=0$ follows analogously. 
Note however once again that the equality of the one-step transition probabilities of the $\left\{\mathrm{X}_{\mathrm{n}}\right\}$ process to those obtained for the usual $\mathrm{M} / \mathrm{M} / 1$ model does not necessarily imply that the $\left\{X_{n}\right\}$ process is a Markov chain or that the stationary distribution of the $\left\{X_{n}\right\}$ process is the same as that given by (3.4).

The "average inter-arrival time", given $T_{1}=x$, is $a=\frac{x+y}{2}=\frac{1}{2}\left(x-\frac{\ln \left(1-e^{-\lambda x}\right)}{\lambda}\right)$.

Thus, conditional upon $\mathrm{T}_{1}=\mathrm{x}, \mathrm{b}=\frac{\text { mean service time }}{\text { mean inter - arrival time }}=\frac{1}{\mu \mathrm{a}}$.

The system will be stable $\Leftrightarrow \mathrm{b}<1 \Leftrightarrow \mu>\frac{1}{\mathrm{a}}=\frac{2}{\mathrm{x}+\mathrm{y}} \Leftrightarrow \frac{\lambda}{\mu}<\frac{\lambda \mathrm{x}-\ln \left(1-\mathrm{e}^{-\lambda \mathrm{x}}\right)}{2}$

\section{Lemma 3.2:}

For the queueing system with arrival process governed by the joint inter-arrival distribution $\mathrm{A}(\mathrm{x}, \mathrm{y})$,

$$
\mathrm{P}\{\text { System is stable }\}= \begin{cases}1, & \text { if } \lambda / \mu<\ln 2, \\ 1-\sqrt{1-4 \mathrm{e}^{-2 \lambda / \mu},} & \text { if } \lambda / \mu \geq \ln 2 .\end{cases}
$$

Proof: First observe that $\mathrm{P}\{$ System is stable $\}=\mathrm{P}\left\{\lambda \mathrm{X}-\ln \left(1-\mathrm{e}^{-\lambda \mathrm{X}}\right)>2 \lambda / \mu\right\}$ where $\mathrm{X}$ is distributed as an exponential $(\lambda)$ r.v. We can evaluate this probability by observing that an equivalent expression is $\mathrm{P}\left\{\left(\mathrm{e}^{-\lambda \mathrm{X}}\right)^{2}-\mathrm{e}^{-\lambda \mathrm{X}}+\mathrm{e}^{-2 \lambda / \mu}>0\right\}=\mathrm{P}\left\{\mathrm{Z}^{2}-\mathrm{Z}+\mathrm{e}^{-2 \lambda / \mu}>0\right\}$ where $Z=e^{-\lambda X}$.

Let the roots of the quadratic in $\mathrm{Z}$ be $\mathrm{z}_{1}$ and $\mathrm{z}_{2}$, where

$$
\mathrm{z}_{1}=\left(1-\sqrt{1-4 \mathrm{e}^{-2 \lambda / \mu}}\right) / 2 \text { and } \mathrm{z}_{2}=\left(1+\sqrt{1-4 \mathrm{e}^{-2 \lambda / \mu}}\right) / 2 \text {. }
$$

Thus $\mathrm{P}\{$ System is stable $\}=\mathrm{P}\left\{\left(\mathrm{Z}<\mathrm{z}_{1}\right) \cup\left(\mathrm{Z}>\mathrm{z}_{2}\right)\right\}=\mathrm{P}\left\{\lambda \mathrm{X}<-\ln \mathrm{z}_{2}\right\}+\mathrm{P}\left\{\lambda \mathrm{X}>-\ln \mathrm{z}_{1}\right\}$

$$
=1-\mathrm{z}_{2}+\mathrm{z}_{1}=1-\sqrt{1-4 \mathrm{e}^{-2 \lambda / \mu}} \text { and the result follows. }
$$

Condition for the roots of the quadratic to be real is that $1-4 \mathrm{e}^{-2 \lambda / \mu} \geq 0 \Leftrightarrow \frac{\lambda}{\mu} \geq \ln 2$.

Otherwise the roots are imaginary and $Z^{2}-Z+e^{-2 \lambda / \mu}>0$ for all $Z$. 
Observe that if $\frac{\lambda}{\mu} \geq \ln 2$, for a particular realisation $\mathrm{T}_{1}=\mathrm{x}$, the system will be stable

$\Leftrightarrow \quad \mathrm{x}<\mathrm{x}_{2}=\frac{-\ln \left(\mathrm{z}_{2}\right)}{\lambda}$ or $\mathrm{x}>\mathrm{x}_{1}=\frac{-\ln \left(\mathrm{z}_{1}\right)}{\lambda}$.

This is as a result of the fact that if a small value of $\mathrm{T}_{1}=\mathrm{x}$ is obtained then a large value for $\mathrm{T}_{2}=\mathrm{y}=-\frac{1}{\lambda} \ln \left(1-\mathrm{e}^{-\lambda \mathrm{x}}\right)$ is obtained. Thus if $\mathrm{x}<\mathrm{x}_{2}$ then automatically $\mathrm{y}>\mathrm{x}_{1}$ and vice-versa, if $\mathrm{x}>\mathrm{x}_{1}$ then automatically $\mathrm{y}<\mathrm{x}_{2}$. The system is however stable for all values of $\mathrm{x}$ (and $\mathrm{y}$ ) if $\lambda / \mu<\ln 2$.

Consider a graphical approach. Observe that from the graph of "a" versus " $x$ ", with $\lambda=$ 1 , a is always greater than $0.693 \ldots=\log 2$. Equivalently from the graph of " $1 / \mathrm{a}$ " versus " $\mathrm{x}$ ", $1 / \mathrm{a}$ is always less than $1 / \ln 2=1.442 \ldots$

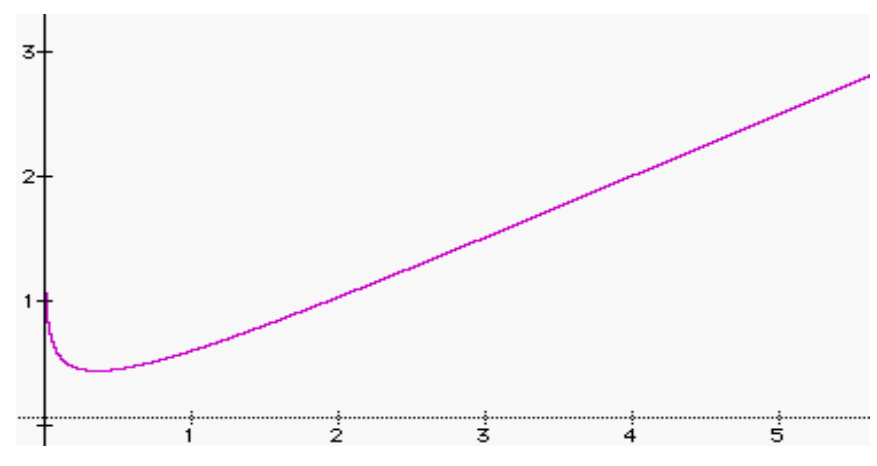

a versus $\mathrm{x}$

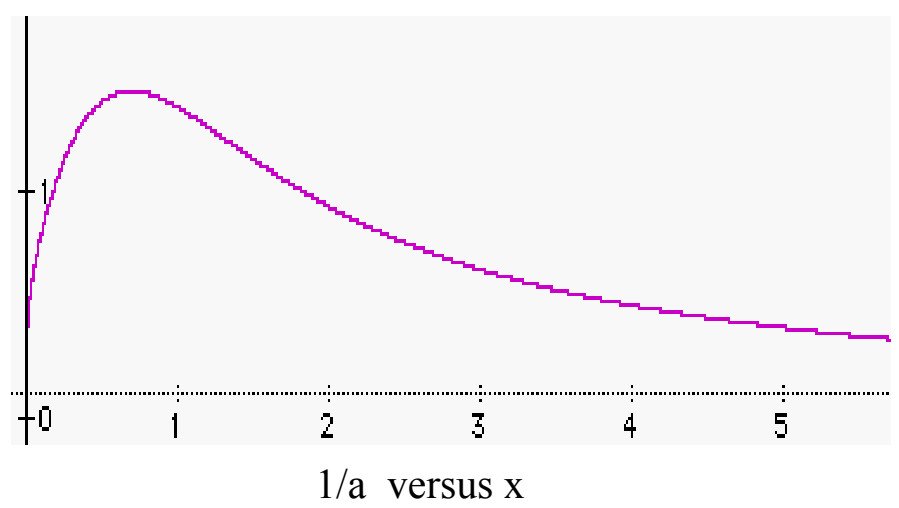


The system will be stable, with probability one, if $\mu>\frac{1}{a}=\frac{2}{x-\ln \left(1-e^{-x}\right)}$ for all $\mathrm{x}$.

i.e. if $\mu>\max _{x>0}\left\{\frac{2}{x-\ln \left(1-e^{-x}\right)}\right\}=\frac{1}{\ln 2}=1.442 \ldots$

Observe that conditional upon $\mathrm{T}_{1}=\mathrm{x}$, (and hence $\mathrm{T}_{2}=\mathrm{y}$ ) the queueing model is in fact a special semi-Markovian $\mathrm{SM} / \mathrm{M} / 1$ queue with the arrivals consisting of two types, 1 and 2, alternating with constant inter-arrival times of length $\mathrm{x}$ and $\mathrm{y}$, respectively. Let $Z_{n}$ be the type of the arrival (either 1 or 2 ) at $t_{n}$, the $n$-th arrival time point, with interarrival times $\mathrm{T}_{\mathrm{n}}=\mathrm{t}_{\mathrm{n}}-\mathrm{t}_{\mathrm{n}-1}\left(\right.$ with $\mathrm{T}_{0}=0$.)

The Markov renewal kernel for the arrival process $\left\{Z_{n}, T_{n}\right\}$ is given by the $2 \times 2$ matrix $\mathbf{A}(\mathrm{t})=\left[\mathrm{A}_{\mathrm{ij}}(\mathrm{t})\right]$ where $\mathrm{A}_{\mathrm{ij}}(\mathrm{t})=\mathrm{P}\left\{\mathrm{Z}_{\mathrm{n}+1}=\mathrm{j}, \mathrm{T}_{\mathrm{n}+1} \leq \mathrm{t} \mid \mathrm{Z}_{\mathrm{n}}=\mathrm{i}\right\}$.

Thus conditional upon $\mathrm{T}_{1}=\mathrm{x}, \mathbf{A}(\mathrm{t})=\left[\begin{array}{cc}0 & \mathrm{U}_{\mathrm{x}}(\mathrm{t}) \\ \mathrm{U}_{\mathrm{y}}(\mathrm{t}) & 0\end{array}\right]$, where $\mathrm{U}_{\mathrm{x}}(\mathrm{t})= \begin{cases}0, & \mathrm{t}<\mathrm{x}, \\ 1, & \mathrm{x} \leq \mathrm{t} .\end{cases}$

Using the formulation for the SM/M/1 queueing model of Cinlar (1967) and Neuts (1978), (see also Neuts (p162-3, 1981)), the queueing model $\left\{X_{n}, Z_{n}, t_{n}\right\}$ can be examined using Markov renewal theory. In particular $\left\{X_{n}, Z_{n}, t_{n}\right\}$ is a Markov process and $\left\{X_{n}, Z_{n}\right\} \quad(n=0,1,2 \quad .$.$) is a Markov chain. The state space of this chain can be$ represented as $\{(i, j), i=0,1,2, \ldots, j=1,2\}$. The one-step transition matrix for this

Markov chain has the form $\mathrm{P}=\left[\begin{array}{lllll}\mathrm{B}_{0} & \mathrm{~A}_{0} & 0 & 0 & \ldots \\ \mathrm{B}_{1} & \mathrm{~A}_{1} & \mathrm{~A}_{0} & 0 & \ldots \\ \mathrm{B}_{2} & \mathrm{~A}_{2} & \mathrm{~A}_{1} & \mathrm{~A}_{0} & \ldots \\ \cdot & . & . & . & \cdots \\ . & . & . & . & \ldots\end{array}\right]$, where the elements are all $2 \times 2$ matrices given by $\mathrm{B}_{\mathrm{n}}=\sum_{\mathrm{k}=\mathrm{n}+1}^{\infty} \mathrm{A}_{\mathrm{k}}=\mathrm{A}-\sum_{\mathrm{k}=0}^{\mathrm{n}} \mathrm{A}_{\mathrm{k}}, \quad \mathrm{A}=\sum_{\mathrm{k}=0}^{\infty} \mathrm{A}_{\mathrm{k}}=\left[\begin{array}{ll}0 & 1 \\ 1 & 0\end{array}\right]$, where $A_{k}=\int_{0}^{\infty} \frac{(\mu t)^{k} e^{-\mu t}}{k !} d A(t)=\left[\begin{array}{cc}0 & p_{k}(x) \\ p_{k}(y) & 0\end{array}\right]$ with $p_{k}(x)=\frac{(\mu x)^{k} e^{-\mu x}}{k !}$.

Note that $B_{n}=\left[\begin{array}{cc}0 & t_{n}(x) \\ t_{n}(y) & 0\end{array}\right]$ with $t_{n}(x)=\sum_{k=n+1}^{\infty} p_{k}(x)$

The necessary and sufficient conditions for stability are (Neuts $(\mathrm{p} 202,1978)) \pi^{\prime} \gamma>\frac{1}{\mu}$, where $\pi^{\prime}=\left(\frac{1}{2}, \frac{1}{2}\right)$ is the invariant distribution of $A$ and $\gamma \quad \mathrm{s}$ the vector of row sum 
means of the semi-Markov kernel $\mathbf{A}(\mathrm{t})$ with $\gamma^{\prime}=(\mathrm{x}, \mathrm{y})$, i.e. $\frac{1}{2}(\mathrm{x}+\mathrm{y})>\frac{1}{\mu}$ (as explored in (3.6)).

Note that the order of the states for the transition matrix $P$ of $\left\{X_{n}, Z_{n}\right\}$ is $\{(0,1),(0,2)$; $(1,1),(1,2) ;(2,1),(2,2) ;(3,1),(3,2) ; \ldots\}$. If we now re-order that states as $\{(0,1),(1,1)$, $(2,1),(3,1),(3,2), \ldots ;(0,2),(1,2),(2,2),(3,2), \ldots\}$ the transition matrix can be reexpressed as $\hat{\mathrm{P}}=\left[\begin{array}{cc}0 & \mathrm{P}(\mathrm{x}) \\ \mathrm{P}(\mathrm{y}) & 0\end{array}\right]$ where $\mathrm{P}(\mathrm{x})=\left[\begin{array}{lllll}\mathrm{t}_{0}(\mathrm{x}) & \mathrm{p}_{0}(\mathrm{x}) & 0 & 0 & \ldots \\ \mathrm{t}_{1}(\mathrm{x}) & \mathrm{p}_{1}(\mathrm{x}) & \mathrm{p}_{0}(\mathrm{x}) & 0 & \ldots \\ \mathrm{t}_{2}(\mathrm{x}) & \mathrm{p}_{2}(\mathrm{x}) & \mathrm{p}_{1}(\mathrm{x}) & \mathrm{p}_{0}(\mathrm{x}) & \ldots \\ . & . & . & . & \ldots \\ . & . & . & . & \ldots\end{array}\right]$.

Under the irreducibility conditions the stationary distribution $\left\{x_{i j}\right\},(i=0,1,2, \ldots ; j=$ $1,2)$ of the Markov chain $\left\{X_{n}, Z_{n}\right\}$ exists. Let $x_{1}^{\prime}=\left(x_{01}, x_{11}, x_{21}, x_{31}, \ldots\right)$ and $\mathbf{x}_{2}^{\prime}=\left(\mathrm{x}_{02}, \mathrm{x}_{12}, \mathrm{x}_{22}, \mathrm{x}_{32}, \ldots\right)$ then $\mathbf{x}^{\prime} \widehat{\mathrm{P}}=\mathbf{x}^{\prime}$ implies $\mathbf{x}_{1}^{\prime}=\mathbf{x}_{2}^{\prime} \mathrm{P}(\mathrm{y})$ and $\mathbf{x}_{2}^{\prime}=\mathbf{x}_{1}^{\prime} \mathrm{P}(\mathrm{x})$. Hence $x_{1}^{\prime}=x_{1}^{\prime} P(x) P(y)$ and $x_{2}^{\prime}=x_{2}^{\prime} P(y) P(x)$. i.e. $x_{1}^{\prime}$ and $x_{2}^{\prime}$ are scaled stationary probability vectors for Markov chains with transition matrices $\mathrm{P}(\mathrm{x}) \mathrm{P}(\mathrm{y})$ and $\mathrm{P}(\mathrm{y}) \mathrm{P}(\mathrm{x})$, respectively. Since $\hat{\mathrm{P}}$ is the transition matrix of a periodic Markov chain, a limiting distribution may not necessarily exist for the Markov chain $\left\{X_{n}, Z_{n}\right\}$. The results given by Neuts and Cinlar typically require the Markov chain $\left\{X_{n}\right\}$ to be ergodic and consequently they cannot necessarily be applied to this model.

Szekli, Disney and Hur (1994) also examine a two-state SM/M/1 queue (that they call a $\mathrm{MR} / \mathrm{M} / 1$ queue). They introduce generating functions to find expressions for the $\mathrm{E}\left[\mathrm{X}_{\mathrm{n}}\right]$. We intend to explore this approach further in a follow-up study.

\subsection{Model 4: Downton's bivariate exponential distribution}

For this model we consider the queue through the process $\left\{\mathrm{X}_{\mathrm{n}}\right\}$ with the inter-arrival pairs $\left(T_{n}, T_{n+1}\right)$ having j.p.d.f given by (1.1).

First note that the marginal p.d.f. of $X=T_{n}$ is given by $f_{1}(x)=\lambda e^{-\lambda x}$. The conditional p.d.f. of $\mathrm{Y}=\mathrm{T}_{\mathrm{n}+1}$ given $\mathrm{X}=\mathrm{T}_{\mathrm{n}}=\mathrm{x}$ is given by

$$
\mathrm{f}_{2}(\mathrm{y} \mid \mathrm{x})=\frac{\lambda}{1-\rho} \sum_{i=0}^{\infty} \frac{1}{\mathrm{i} ! \mathrm{i} !}\left(\frac{\rho \lambda \mathrm{x}}{1-\rho}\right)^{\mathrm{i}}\left(\frac{\lambda \mathrm{y}}{1-\rho}\right)^{\mathrm{i}} \exp \left\{-\frac{\rho \lambda \mathrm{x}+\lambda \mathrm{y}}{1-\rho}\right\},
$$

where we have used the series expansion for $\mathrm{I}_{0}($.$) .$ 
For $1 \leq \mathrm{j} \leq \mathrm{i}+1$,

$$
\begin{aligned}
P\left[X_{1}=j \mid X_{0}=i\right] & =\int_{0}^{\infty} P\left[X_{1}=j, T_{1} \in(x, x+d x) \mid X_{0}=i\right] \\
& =\int_{0}^{\infty} P\left[X_{1}=j \mid X_{0}=i, T_{1}=x\right] \lambda e^{-\lambda x} d x=k_{i+1-j}
\end{aligned}
$$

This integral is the expectation of $\frac{e^{-\mu Y}(\mu Y)^{i+1-j}}{(i+1-j) !}$ and thence, since $\mathrm{f}_{2}(\mathrm{y})=\lambda \mathrm{e}^{-\lambda \mathrm{y}}$, $P\left\{X_{2}=j \mid X_{1}=i\right\}=\int_{0}^{\infty} \frac{e^{-\mu y}(\mu y)^{i+1-j}}{(i+1-j) !} \lambda e^{-\lambda y} d y=k_{i+1-j}$, as derived for the $M / M / 1$ model, equation (3.3). Similarly we can derive analogous results when $\mathrm{j}=0$.

With a similar derivation, we can derive identical expressions for $P\left[X_{n+1}=j \mid X_{n}=i\right]$, $(n \geq 0)$ to those obtained for the $M / M / 1$ model.

Pyke Tin (1985) in examining the transient behaviour of the queue size distribution via the joint distribution $P\left\{X_{n}=j, T_{n} \leq t \mid X_{0}=i\right\}$, for this model, showed that for $0<\rho<1$ and $\lambda<\mu$,

$$
\pi_{\mathrm{k}}=\lim _{\mathrm{n} \rightarrow \infty} \mathrm{P}\left\{\mathrm{X}_{\mathrm{n}}=\mathrm{k}\right\}=\left\{\begin{array}{cc}
1-\beta \mathrm{T}, & \mathrm{k}=0 \\
\beta(1-\mathrm{T}) \mathrm{T}^{\mathrm{k}}, & \mathrm{k} \geq 1
\end{array}\right.
$$

where

$$
\begin{aligned}
& \mathrm{T}=\left[\rho+\frac{\mu(1-\rho)}{\lambda}\right]^{-1} \\
& \beta=\frac{\mu_{1}-\rho+a(1-\rho) / \lambda}{\left(\mu_{1}-\rho\right)(1+a / \lambda)} . \\
& \mathrm{a}=\frac{-(1-\rho)(1+\mu / \lambda)+\left\{[1+\rho+\mu(1-\rho) / \lambda]^{2}-4 \rho\right\}^{1 / 2}}{2(1-\rho) / \lambda} \\
& \mu_{1}, \mu_{2}=\frac{1}{2}[1+\rho+\mu(1-\mathrm{T}) / \lambda] \pm\left\{[1+\rho+\mu(1-\rho) / \lambda[1-\mathrm{T}]]^{2}-4 \rho\right\}^{1 / 2} .
\end{aligned}
$$

\section{Discussion}

The results obtained for all the four models show that the transition probabilities of the form $P\left[X_{n+1}=j \mid X_{n}=i\right]$, where $X_{n}$ is the queue length embedded immediately prior to an arrival, show no dependence upon the correlation coefficient $\rho$ of the joint distribution between successive arrivals. The form of the particular bivariate distribution used to generate the correlated arrival process is not evident in the expressions for the 
one-step transitions of the $\left\{X_{n}\right\}$ process. In reflection, this is to be expected since the transition probabilities depend in effect only on the marginal distribution of the interarrival times between successive arrivals. However, the conditions for stability of the queue length processes vary markedly with $\lambda<\mu$ for Model 1 when $\rho=0$; with $T_{1}>$ $1 / \mu$ with probability $\exp (-\lambda / \mu)$ for Model 2 when $\rho=1$; with $\lambda T_{1}-\ln \left(1-e^{-\lambda T_{1}}\right)>\frac{2 \lambda}{\mu}$ with probability $1-\sqrt{1-4 \mathrm{e}^{-2 \lambda / \mu}}$ if $\lambda / \mu \geq \ln 2$ and probability 1 otherwise for Model 3 when $\rho=-0.645$; and $\lambda<\mu$ for Model 4 with $0<\rho<1$.

\section{References}

Cinlar E. (1967). Queues with semi-Markovian arrivals. J. Appl. Prob., 4: 365-379

Fréchet M. (1951). Sur les tableaux de correlation dont les marges sont donnees. Ann. Univ. Lyon, A(3), 14: 53-77

Gopinath B., and Morrison J. A. (1977). Single Server Queues with Correlated Inputs. Computer Performance, K. M. Chandy and M. Reiser, eds., North-Holland Publ. Co., 264-277

Hoeffding W. (1940). Masstabinvariante Korrelationstheorie. Schriften Math. Inst. Univ. Berlin, 5: 181-233

Hunter J. J. (1977). Renewal Theory in Two Dimensions: Bounds on the Renewal Function. Adv. Appl. Prob., 9: 527-541

Latouche G. (1985). An Exponential Semi-Markov Process with applications to Queueing Theory. Stochastic Models, 1: 137-170

Latouche G. (1981). On a Markovian Queue with Weakly Correlated Inter-arrival Times. J. Appl, Probab., 18: 190-223

Livny M. Melamed B. and Tsiolis A. K. (1993). The Impact of Autocorrelation on Queueing Systems. Management Science, 39: 322-339

Moran P. A. P. (1967). Testing for Correlation Between Non-Negative Variates. Biometrika, 54, 3 and 4: 385-394

Neuts M.F. (1978). Markov chains with applications in queueing theory, which have a matrix-geometric invariant probability vector. Adv. Appl. Prob., 10: 185-212

Neuts M.F. (1981). Matrix-Geometric Solutions in Stochastic Models, An Algorithmic Approach. The Johns Hopkins University Press, Baltimore 
Patuwo B. E., Disney R. L. and McNickle D. C. (1993). The Effect of Correlated Arrivals on Queues. IIE Transactions, 25, (3): 105-110

Runnenburg J. Th. (1961). An Example Illustrating the Possibilities of Renewal Theory and Waiting Line Theory for Markov Dependent Arrival Intervals. Nederl. Akad. Wetensch. Pro. Ser., A, 64: 560-576

Runnenburg J. Th. (1962). Some Numerical Results on Waiting Time Distributions for Dependent Arrival-Intervals. Statist. Nederlandica, 12: 19-29

Szekli S. Disney R.L. and Hur S. (1994). MR/G/1 queues with positively correlated arrival stream. J. Appl. Prob., 31: 497-514

Sriram K. and Whitt W. (1986). Characterizing Superposition Arrival Processes in Packet Multiplexers for Voice and Data, IEEE J. on Selected Areas in Comm., SAC4: $833-846$

Tin Pyke (1985). A Queueing System with Markov Dependent Arrivals, J. Appl. Prob., 22: $668-677$ 
